\section{Medical students' experience of consulting in primary care}

We are writing to raise an issue that we, and our peers, have come across first hand as medical students consulting about our health.

It is common for doctors to ask you what you study as a student. This piece of information sometimes allows discussions and builds rapport; however, it can result in unwanted consequences. Once revealing you are a medical student it is put in your notes, resulting in this information being known by other doctors before you tell them yourself. Although the need to know the social history of a patient is understandable, at times this can leave you feeling somewhat ambushed. Further, this information results in assumptions being made about you.

Once a doctor is aware that you are a medical student, they often rush over their management plan, assuming higher knowledge than you may have. As medical students, we are often proud, and thus feel unable to interject to ask for an explanation at a lower level.

Another important area where it affects quality of care is mental health. This is a key issue, as approximately one-third of medical students worldwide experience depression. Often it takes individuals time and courage to seek medical help regarding this. It is therefore difficult when you face comments such as 'It's fairly normal at your medical school' or 'Most doctors face burn out at one point.' Although these facts may be true, it reduces the individual feelings despite the troubles they may be facing internally.

Finally, it is not uncommon for students to hide their medical student status when consulting regarding their sexual health, for the fear they may be branded irresponsible for a medical student'. Although this may not be the case, it is certain that medical students are expected to have a responsibility to be champions of excellent health and portray this to their non-medical student counterparts.

Although these experiences do not occur in all consultations, on discussion with peers we found that all had some negative experiences after they disclosed studying medicine. So why is it important? Why is it permanently in my medical records?
Claudia Cohen,

Fifth-Year Medical Student, University of

Birmingham, Birmingham.

Email: Cxc522lastudent.bham.ac.uk

Elizabeth Mairenn Garden,

Fifth-Year Medical Student, University of Birmingham, Birmingham.

Email: mairenngardendyahoo.co.uk

\section{REFERENCE}

1. Moir F. Yielder J, Sanson J, Chen Y. Depression in medical students: current insights. Adv Med Educ Pract 2018; 9: 323-333. DOI: 10.2147/AMEP.S137384.

DOI: https://doi.org/10.3399/bjgp20X712229

\section{How was lockdown for you? Asylum seekers' mental health during the pandemic}

Mulberry Practice, in Sheffield, serves asylum seekers and victims of trafficking. As you can imagine we have a very high prevalence of mental health problems: PTSD, anxiety, and depression. In normal years I see a dip in my patients' mental health when English classes close for the summer holidays. This year the COVID-19 pandemic has meant that not only have English classes ceased but also all the volunteering and socialising opportunities that give my patients a reason to get out of bed in the mornings. I cannot see when these activities will re-open as they are all dependent on volunteers and were already cash strapped.

Imagine lockdown if you: live in a room in a shared house, sharing with strangers who do not speak your language (some of my patients only have a skylight in their room): have no family or friends around you; have only a mobile phone, no broadband, and very little internet data; cannot afford books or crafts lasylum seekers receive just over €5 per day for food, toiletries, bus fare, phone costs, clothing ...); are afraid to go out as you fear you will catch COVID-19 and never see your family again; and had poor mental health at the start of lockdown.

In June, six people were injured and a
Sudanese asylum seeker died, during an incident in a hotel in Glasgow. The hotel was being used to house around 100 asylum seekers. ${ }^{1}$ All the ingredients for acute mental health crises are in place in Glasgow and other cities across the UK where asylum seekers are housed. I would argue that if schools still open (with social distancing) for vulnerable children during lockdown, then there are also vulnerable adults for whom some structured daily activities should still be provided. Mental wellbeing is not an optional extra. It depends on the ability to connect to others: be physically active; learn new skills; and give to others as well as taking notice. ${ }^{2}$ It is time to take notice of how we are caring for the most vulnerable members of our society.

Pip Fisher,

GP, Mulberry Practice, Sheffield; Senior Lecturer - Lead for Student Wellbeing, University of Manchester, Manchester. Email: Pip.Fisherdamanchester.ac.uk

\section{REFERENCES}

. Alderson R. Glasgow stabbings: concerns over asylum hotel plan ahead of incident. BBC News 2020; 27 Jun: https://www.bbc.co.uk/news/ uk-scotland-53205396 laccessed 4 Aug 2020).

2. Foresight. Mental capital and wellbeing: final project report. London: Government Office for Science, 2008.

DOI: https://doi.org/10.3399/bjgp20X712241

\section{Atrial fibrillation: beware of the government gap}

In April this year, Public Health England (PHE) published estimated rates of atrial fibrillation (AF) for local CCGs in England,' claiming that Healthcare professionals can use this resource to estimate the number of people with atrial fibrillation in their local area. The data also shows the variation in the condition across the local area. This can help with planning and commissioning local services."

Unfortunately, these estimates are grossly inflated. They bear little resemblance to local reality and may be misused to erroneously claim that GPs are 